April - 2009

Regional Focus Issue: Bridge over Troubled Waters Cengiz Hakan Aydin and Yoram EshetAlkalai, IRRODL Regional Editors for the Middle East

\title{
Psychosocial Well-Being of Israeli Students and Attitudes toward Open and Distance Learning
}

\author{
Gila Kurtz \\ The Centre for Academic Studies, Israel \\ Yair Amichai-Hamburger \\ Interdisciplinary Center Herzelia, Israel \\ Jeffrey Kantor \\ Bar-Ilan University \& Ariel University Center, Israel
}

\begin{abstract}
This article reports on a study conducted in Israel at an academic institution. The study investigates the correlation between students' attitudes toward open and distance learning (ODL) and their perceived self-esteem and loneliness at the last stage of their online learning experience. For this study, 120 students were asked to complete a questionnaire. The students were enrolled in three fully online academic courses, which were similar in their instructional design approach although different in content. Findings reveal that there is a positive correlation between selfesteem and attitudes toward e-learning in general and toward online interaction with the instructor in particular. The findings further suggest that there is no correlation between loneliness and student attitudes toward e-learning. Some explanations for these results are raised as are recommendations for further research.
\end{abstract}

Keywords: attitudes toward ODL; perceived well-being; UCLA Loneliness Scale; fully online courses

\section{Introduction}

The use of the Internet is becoming increasingly influential in our daily life. Internet technology is developing at an astounding rate. The pace and scale of these changes for the whole of society are such that this phenomenon has been compared to the "Industrial Revolution" of the nineteenth century and dubbed the "Internet Revolution” (Amichai-Hamburger, 2002). 
The educational arena is no exception. The open and distance learning (ODL) revolution, which can be aptly described using the terms e-learning (electronic learning) and online learning to refer to the implementation of the Internet in the learning process, is here and now (Moore \& Kearsley, 2005). Based on Kurtz et al. (2003), we define ODL as an interactive teaching-learning process, in which at least part of it is done online by means of text/audio/video.

With the growth of online courses, it is critical to ensure the success of students in the online environment. Much research has been done on online students' perceptions, satisfactions, motivation, and cognitive and learning styles, and how these factors influence student achievement in online courses (Fahy \& Ally, 2005; Young, 2006; Bates \& Khasawneh, 2007; Offir, Bezalel, \& Barth, 2007).

A particularly relevant variable for understanding people's behavior on the Internet is personality. Hamburger and Ben-Artzi (2003) pointed out that personality can serve as a leading explanation for differential behavior of surfers on the Internet. Many personality characteristics, such as introversion and extroversion (Hamburger \& Ben-Artzi, 2003), need for closure (AmichaiHamburger, Fine, \& Goldstein, 2004), need for cognition (Amichai-Hamburger \& Kinar, 2007), locus of control (Hoffman, Novak, \& Schlosser, 2003), and sensation seeking (Alonzo, \& Aiken, 2004), have been suggested as reasons to explain Internet behavior. Based on the research cited in this section, personality traits seem to constitute relevant variables in understanding people's behavior on the Internet and we can assume also in the e-learning environment.

This research investigates the correlation between students' attitudes toward ODL and their perceived self-esteem and loneliness at the last stage of their online and face-to-face learning experience. The analysis focuses on three undergraduate online courses similar in their instructional design approach but different in content: two courses are on the topic of quantitative research and one is on the state and government in Israel.

The courses were designed to be self-paced so that students would study independently within a timeframe that was set by the instructor. The courses' content and educational activities (including assignments) were carried out through an asynchronous learning management system (LMS).

\section{Theoretical Background}

\section{The Internet in its Psychological Context}

The Internet creates a unique psychological environment for the online user. McKenna, Green, and Gleason (2002) suggest four major factors that differentiate Internet interactions from faceto-face interactions:

\section{(1) Greater anonymity}

On the Internet, people can easily maintain their anonymity. Internet sites differ as to the degree of anonymity they allow the user to maintain. However, even when users provide their real names 
or disclose other personal details or private information, they still feel relatively anonymous (McKenna \& Bargh, 2000). This feeling of anonymity frees people from social norms and encourages them to express themselves and behave more freely and sincerely than they would normally in face-to-face interactions.

(2) Diminution of the importance of physical appearance

Physical appearance is one of the focal determinants of how we are perceived by others (Fiske \& Taylor, 1991). Cialdini (1984) suggested that attractive people have enormous social advantages, they are seen as possessing superior personality traits and intellectual capabilities, and they are better liked and more frequently helped. These benefits are bestowed due to what is termed as the halo effect. This occurs when one positive characteristic of a person, such as attractiveness, leads the perceiver to believe that other positive characteristics are present, e.g. an attractive male may be perceived as honest and caring. Just as the halo effect plays in favor of the physically attractive, conversely people who are physically unappealing will frequently find that they are judged unfavorably on any number of unrelated aspects. In an online environment, people are freed from being appraised by others based on physical characteristics.

Since a major part of Internet interaction is text-based, the physical characteristics of the participants remain undisclosed. This factor will be particularly significant for people with unsightly or unattractive physical characteristics, who are very likely to suffer from discrimination in a face-to-face interaction. On the Internet such people have an opportunity to present themselves in any way they choose. They may hope that if and when the interaction will move on to become face-to-face, any negative physical features will not be relevant.

This freedom may help them form a new basis for their interaction with others and help strengthen their self-image and self-confidence. Whilst offline, such people may have internalized a negative social perception of themselves, but interaction over the Internet may give them opportunities to reframe their self perception.

\section{(3) Greater control over the time and pace of interactions}

One of the unique facets of Internet communication is that for the participant the whole encounter is taking place in an environment of his or her choosing, and this may be a source of security and comfort. The Internet user is able to go out to meet the world from his/her living room (Mandell \& Muncer, 2007). Another source of security comes from the opportunity Internet users have to review their statements before sending them. This type of thought and review process does not exist in face-to-face encounters because they take place in real-time. This progression of writing and then reviewing on the screen creates a higher self-awareness since the writer observes him/herself as an object (Duval \& Wicklund, 1972).

\section{(4) Finding similar others}

The need to belong is listed as one of the significant needs in Maslo's (1971) Hierarchy of Needs. Being a member of a group that shares your goals and interests is likely to enhance self-esteem (Tajfel \& Turner, 1986), which is believed to be very important for well-being (Branden, 1969). 
The Internet is visited every day by millions of surfers, all of whom have varied interests. It is easy to find details about the different interest groups on the Internet, which facilitates the discovery of like-minded others who are visiting the same site. This is often particularly relevant to people who belong to stigmatized groups or to very small groups since they are likely to find it difficult to get together with others in non-Internet environments. It was found that on the Internet people sometimes develop group identifications even faster than offline groups (McKenna, Green, \& Gleason, 2002).

Interaction in an online learning event is a crucial component of the education process (Anderson, 2003). Anderson and Garrison (1998) described the three most common types of interaction involving students, which are discussed in the distance education literature: student-student, student-teacher, and student-content. All three types of interaction share similarities with the online interaction characteristics described above: students can maintain some anonymity within the learning activities; they are freed from being appraised by others based on physical characteristics; and they can study unconstrained by time and place. By sharing common learning goals with their classmates they can develop what Anderson (2008) calls "a community-centered context." It seems that lonely people will derive greater enjoyment than their non-lonely counterparts from participating in the e-learning environment since the opportunities it provides for significant social interaction compensates them for their previously unsatisfied social needs.

\section{Self-Esteem}

Self-esteem is defined as an individual's overall negative or positive attitude towards himself or herself (Rosenberg \& Simmons, 1975) or as one’s belief regarding how well one is living up to the standards of value prescribed by one's society (Harmon-Jones et al. 1997). Baumeister et al. (2003) pointed out that one of the components necessary to achieve a true rise in self-esteem is successful performance in a learning task. Moreover, since modern society places a value on the mastery of technology, it would appear that taking an e-learning course would enhance selfesteem.

\section{Research Hypotheses}

In conducting the research presented in this paper, two hypotheses were proposed:

1. Students with high self-esteem will be associated with positive attitudes toward online learning and a greater preference for online learning when compared to students with low self-esteem.

2. Lonely students, when compared to students who are less lonely, will express positive attitudes toward online learning and will choose online learning as their preferred mode of learning over the face-to-face mode.

\section{Research Method}


The sample comprised 120 students who completed questionnaires while attending a face-to-face meeting a few days before the final exam in summer, 2007. The students were enrolled in three fully online undergraduate courses. The students were not required to attend this face-to-face meeting. This fact explains the relatively small sample of students, which was $19 \%$ of all students enrolled in the three courses. Statistical analysis revealed no significant differences between the students in the three courses in regards to personal traits or attitudes toward e-learning. The 'no significant difference' result led us to the decision to refer to the 120 students as a unified group.

Student loneliness was measured using the revised UCLA Loneliness Scale from Russell, Peplau, and Cutrona (1980). The UCLA scale contains 20 positive and negative statements about one's social relations. Participants rated each statement according to applicability, using a 4-point scale from not at all (1) to very much (4).

Self-esteem was measured using Heatherton and Polivy’s (1991) State Self-Esteem Scale (SSES). This scale consists of 20 positive and negative statements about one's self-concept, ranking from 1-lowest (negative) to 5-highest (positive).

The attitude toward Online Learning Scale (OLS) was adapted from research by Kurtz, Sagee, and Getz-Lengerman (2003). The OLS consists of 14 items that examine aspects of beliefs, preferences, and satisfaction, all related to online learning and ranking from 1-lowest (negative) to 5-highest (positive). In addition, students were asked to state their preferred mode of learning: (1) only face-to-face; (2 )only online; (3) blended (i.e., face-to-face and online), or (4) no preference. This question served as a concluding question that summarized the OLS items.

\section{Results}

\section{Students' Background Variables}

Most respondents to the questionnaire were female (72.8\%); $62.5 \%$ were married, and $35.7 \%$ were single; more than $60 \%$ of the students stated that their family income is average compared to the general or above; about $50 \%$ were under the age of 30, ranging in ages from 21 to $57(\mathrm{M}=$ 32.8 , $\mathrm{SD}=8.88$ ); and for half the students, the course was their first online course.

\section{Hypothesis 1: State Self-Esteem and Attitudes toward E-Learning}

The mean score of the SSES was $3.8(\mathrm{SD}=0.49)$ and the mean score of the OLS was $3.2(\mathrm{SD}=$ 0.68). Pearson correlations conducted between SSES and OLS revealed a positive relationship between the scales $(r=+.33, p=0.00, n=110)$. This result indicates that students with high selfesteem are more likely to express positive attitudes about online learning.

To further examine the correlation between the two indices, we divided both indices into factors. Based on Kurtz, Sagee, and Getz-Lengerman (2003), we divided the OLS into two factors. The first factor was attitudes toward online learning in general factor (accounted variance $=43.1 \%$, 
$\mathrm{M}=3.4, \mathrm{SD}=0.76)$. The second factor was attitudes toward the course in regard to the interaction with the instructor factor (accounted variance $=13.4 \%, \mathrm{M}=2.5, \mathrm{SD}=0.93$ ).

Although Heatherton and Polivy (1991) identified three factors within the SSES, we found only one significant factor, which was the performance self-esteem factor (coefficient alpha of .69). The mean score of the performance self-esteem factor was $4.2(\mathrm{SD}=0.60)$.

Pearson correlation shows that the performance self-esteem factor is highly and positively correlated with the attitudes toward online learning in general factor $(r=+0.38, p<0.01, n=$ 113), but that there is no significant correlation with the interaction with the instructor factor. These results provide additional empirical support for the tendency that students with high selfesteem are more likely to express positive attitudes toward online learning.

The association between the SSES with the preferred mode of learning reveals a significant correlation between the variables (chi-square $=112.73, d f=118, p<0.04$ ). There was also a significant correlation of the SSES with the students who prefer an online mode of learning $(n=$ $11)$ and with fewer students who prefer face-to-face learning $(n=25)(\mathrm{t}=-1.638, \mathrm{df}=31, p<$ $0.01)$.

These results indicate that the first hypothesis was confirmed. Students who prefer an online mode of learning are likely to rate themselves as having a higher self-esteem than those students who prefer learning face-to-face. Katz and Offir (1990) add an additional support for the first hypothesis. They found that positive computer-oriented attitudes are related to self-esteem and school motivation and satisfaction. Pupils with positive self-esteem prefer study through the medium of computer assisted learning.

\section{Hypothesis 2: Loneliness and Attitudes toward E-Learning}

Pearson correlation between loneliness and the OLS did not reveal a significant relationship between the variables. Also, the chi-square test between the UCLA Loneliness Scale and the students' preferred mode of learning did not reveal a significant correlation between the variables.

Overall, the second hypothesis was not substantiated, i.e., no correlation was found between student loneliness and student attitudes toward e-learning and preferred mode of learning.

\section{Conclusion}

The current paper investigated the correlation of the psychosocial well-being of students in the last stage of their learning in online courses with their attitudes toward e-learning. The analysis focuses on three undergraduate online courses similar in their instructional design approach but different in content.

Two hypotheses were proposed: the first was confirmed; the second was not. The results for the first hypothesis confirmed the hypothesis and suggested a correlation in accordance with our 
prediction. Students' self-esteem was positively related to attitudes toward online learning and to a greater preference for online learning. As for the second hypothesis, no statistically significant relationship between student loneliness and attitudes toward e-learning and preferred mode of learning was found.

There are a number of possible explanations for our failure to confirm the second hypothesis. It could be that the instructional design of the online courses did not allow much student control over the learning process, nor did it allow students to maintain their anonymity within the learning process. The instructional design of all three courses was not student-centered. A student-centered approach places the focus and the control of learning into the hands of the learner (Barr \& Tagg, 1995), while emphasizing the development of a sense of learning community that binds learners and teachers through shared values, ideals, and goals (Sergiovanni, 1994). In our research study, the courses were delivered using an object-based approach to learning in an LMS that organizes and standardizes learning content, dividing the course into modules and lessons and supported with quizzes, tests, and discussions (Downes, 2005).

Students were required to participate in class discussions/assignments within specific dates, and the instructor could track their activities in class at any time. This requirement did not follow the first principle of good teaching practice that encourages contact between students and faculty. Frequent student-faculty contact in and out of class is an important factor in student motivation and involvement (The American Association of Higher Education's Seven Principles for Good Practice in Undergraduate Education, cited in Caplan \& Graham, 2008). By putting in place a more indirect opportunity for guidance using distance technologies, faculty interactions with all students (especially with shy students who are reluctant to ask questions or challenge the teacher directly) can be strengthened. It is often easier to discuss values and personal concerns in writing than orally since inadvertent or ambiguous nonverbal signals are not so dominant (Chickering \& Gamson, 1987, as cited in Caplan \& Graham, 2008). These explanations can help us better understand why the second hypothesis was not substantiated.

\section{Recommendations for Future Research}

We do not intend to generalize these results to a wider population. However, our participants offered us food for thought, providing interesting correlations that need to be explored further. In our opinion, it would be important to extend the research to a comparative study with a control group that would study the same content but in the traditional face-to-face method. It would also be useful to extend the research to include representative groups of students who differ in their psychological traits and Internet experience. Also, longitudinal research that samples the same students at different points in time is needed to identify trends and changes in psychosocial wellbeing and attitudes toward e-learning. It would also be important to extend this research to courses with a different instructional design to the one presented here. For example, research could be conducted on online courses that allow greater control over the learning process and emphasize collaborative work and personal contribution while at the same time offering students the possibility to maintain their anonymity. Finally it is important to study e-learning environments that include significant social interactions. In such a case, one would be able to 
examine if the face-to-face environment that it is substituting might make it a more favorable place for people with social inhibitions. 


\section{References}

Alonzo, M. \& Aiken, M. (2004). Flaming in electronic communication. Decision Support Systems, 36(3), 205-338.

Amichai-Hamburger, Y. (2002). Internet and personality. Computers in Human Behavior, 18, $1-10$.

Amichai-Hamburger, Y., \& Ben-Artzi, E. (2003). Loneliness and internet use. Computers in Human Behavior, 19, 71-80.

Amichai-Hamburger, Y., \& Kinar, O. (2007). The effects of need for cognition on Internet use. Computers in Human Behavior, 23, 880-891.

Anderson, T. (2003). Getting the mix right again: An updated and theoretical rationale for interaction. The International Review of Research in Open and Distance Learning 4(2). http://www.irrodl.org/index.php/irrodl/article/view/149/230

Anderson, T. (2008). Towards a theory of online learning. In T. Anderson (Ed.), Theory and practice of online learning (pp. 45-74). Athabasca, AB: AU Press. http://www.aupress.ca/books/Terry_Anderson/anderson2.pdf

Anderson, T., and Garrison, D.R. (1998). Learning in a networked world: New roles and responsibilities. In C. Gibson (Ed.), Distance Learners in Higher Education. (p. 97-112). Madison, WI: Atwood Publishing

Barr, R. B., and Tagg, J. (1995). From teaching to learning: A new paradigm for undergraduate education. Change, 27(6), $13-25$.

Bates, R., \& Khasawneh, S. (2007) Self-efficacy and college students' perceptions and use of online learning systems. Computers in Human Behavior, 23(1), 175-191.

Branden, N. (1969). The psychology of self-esteem: A new concept of man's nature. Los Angeles: Nash Publishing.

Baumeister, R.F., Campbell, J.D., Krueger, J.I. \& Vohs, K.D. (2003). Does high self-esteem cause better performance interpersonal success, happiness, or healthier lifestyles? Psychological Science in the Public Interest, 4, 1-44.

Brodie, M., Flournoy, R. E., Altman, D. E., Blendon, R. J., Benson, J. M., \& Rosenbaum, M. D. (2000). Health information, the Internet, and the digital divide. Health Affairs, 19(6), 255-265

Cialdini, R. B. (1984). Influence: The new psychology of modern persuasion. New-York: Quill.

Caplan, D., \& Graham, R. (2008). The development of online courses. In T. Anderson (Ed.), Theory and practice of online learning. (pp.245-264). Athabasca, AB: AU Press. http://www.aupress.ca/books/Terry_Anderson/caplan.pdf

Cheurprakobkit, S., Hale, D.F., \& Olson, J. N. (2002). Technicians’ perceptions about web- 
based courses: the University of Texas system experience. The American Journal of Distance Education, 16(4), 245-258.

Council for Higher Education (1999). A call for projects: Designing an overall teaching/learning system based on advanced technologies. Jerusalem: The Budgeting and Planning Committee of the Council for Higher Education (in Hebrew).

Downes, S. (2005). Are the basics of instructional design changing?

Stephen's web. http://www.downes.ca/cgi-bin/page.cgi?post=6

Duval, S. R., \& Wiklund, R. A. (1972). Theory of objective self awareness. Academic Press: New York.

Fahy, P. J., \& Ally, M. (2005). Student learning style and asynchronous computer-mediated conferencing (CMC) interaction. American Journal of Distance Education, 19(1), 5-22.

Finn, J., Kerman, B., \& LeCornec, J. (2004). Building skills-building futures: Providing information technology to foster families. Families in Society, 85(2), 165-176.

Fiske, S. T., \& Taylor, S. E. (1991). Social cognition (2 ${ }^{\text {nd }}$ ed.). New York: McGraw-Hill.

Harmon-Jones, E., Simon, L., Greenberg, J., Pyszczynski, T., Solomon, S., \&

McGregor, H. (1997). Terror management and self-esteem: Evidence that self-esteem reduces mortality salience effects. Journal of Personality and Social Psychology, 72, 2426.

Heatherton, T.F., \& Polivy, J. (1991). Development and validation of a scale for measuring state self-esteem. Journal of Personality and Social Psychology, 60, 895-910.

Hoffman, D.L., Novak, T.P., \& Schlosser, A. (2003). Consumer attitudes toward software filters and online content ratings: A policy analysis. Journal of Public Policy and Marketing, 22(1), 41- 57.

Katz, Y.J. and Offir, B. (1990) Computer assisted instruction and students' social orientations. Proceedings of 5th Jerusalem Conference on Information Technology (pp. 660-664). Los Alamitos, CA: IEEE Computer Society Press.

Kurtz, G., Sagee, R., \& Getz-Lengerman, R. (2003). Alternative online pedagogical models with identical contents: A comparison of two university-level courses. The Journal of Interactive Online Learning, 2(1). http://www.ncolr.org/jiol/issues/PDF/2.1.2.pdf

Kurtz, G., Teeni, D., Mevarech Z., \& Neuthal, T. (2006). The experience of implementing instructional technology in Israel higher education. In M. Beaudoin (Ed.), Perspectives on higher education in the digital age. New York: Nova Science Publishers.

Loyd, B.H., \& Gressard, C. (1984). The effects of sex, age, and computer experience on computer attitudes. AEDS Journal, 18(2), 67-77.

Madell, D., \& Muncer, S. (2007). Control over social interactions: An important reason for 
young people's use of the Internet and mobile phones for communication? Cyber Psychology \& Behavior, 10(1), 137-140

McKenna, K. Y., Green, A. S., \& Gleason, M. E. J. (2002). Relationship formation on the Internet: What's the big attraction? Journal of Social Issues 58(1), 9-31.

Maslow, A. (1971). The farther reaches of human nature. New York: The Viking Press.

Moore, M. G., \& Kearsley, G. (2005) Distance education: A systems view (2 ${ }^{\text {nd }}$ ed.). Belmont, CA: Wadsworth.

Norris, P. (2001). Digital divide? Civic engagement, information poverty, and the Internet worldwide. Cambridge: Cambridge University Press

Offir, B., Bezalel, R., \& Barth, I. (2007). Introverts, extroverts, and achievement in a distance learning environment. American Journal of Distance Education, 21(1), 3-19.

Rosenberg, F. R., \& Simmons, R. G. (1975). Sex differences in the self-concept in adolescence. Sex Roles, 1(2), 147-159.

Rubin, Z. (1975). Disclosing oneself to a stranger: Reciprocity and its limits. Journal of Experimental Social Psychology 11, 233-260

Russell, D., Peplau, L. A., \& Cutrona, C.E. (1980). The revised UCLA loneliness scale: Concurrent and discriminate validity evidence. Journal of Personality and Social Psychology 39, 472-480

Sergiovanni, T. J. (1994). Building community in schools. San Francisco: Jossey-Bass.

Tajfel, H., \& Turner, J. C. (1986). The social identity theory of inter-group behavior. In S. Worchel \& L.W. Austin (Eds.), Psychology of inter-group relations. Chicago: NelsonHall.

Young, S. (2006). Student views of effective online teaching in higher education. American Journal of Distance Education, 20(2), 65-77. 